\title{
EL MONASTERIO DE SANTA MARTA. PROCESO DE RESTAURACIÓN Y CONSERVACIÓN DE LA PORTADA DE LA IGLESIA CONVENTUAL DE LA ORDEN DE CLAUSURA DE LAS HERMANAS JERÓNIMAS EN CÓRDOBA, ESPAÑA ${ }^{[*]}$
}

\author{
THE SANTA MARTA MONASTERY. PROCESS OF RESTORATION AND CONSERVATION OF THE FRONT OF \\ THE CONVENT CHURCH OF THE ORDER OF CLOSURE OF HYERONIMITE SISTERS IN CORDOBA, SPAIN
}

\author{
NOEMA WIS MOLINO ${ }^{(* *]}$ \\ Fecha de recepción: 22 de octubre de 2016 \\ Fecha de aprobación: 23 de noviembre de 2016
}

\begin{abstract}
RESUMEN
En los albores del siglo XII, se producía en los Reinos de España la caída del Imperio musulmán y la toma de Córdoba. El proceso de Reconquista comenzó en el suroeste de Andalucía, por la provincia de Jaén, y continuó hacia la ciudad más importante de los territorios del Al Ándalus, Córdoba. Se inició una nueva etapa en la historia y el arte, influenciada por las corrientes del Reino de Castilla, ya bajo la dominación de los reyes cristianos. Durante esta nueva etapa surgieron en la ciudad nuevas tipologías arquitectónicas con finalidad religiosa, los palacios-conventos. Uno de los más importantes es el convento de Santa Marta y su iglesia, un hito en la arquitectura de finales del gótico, gracias a la familia de canteros y escultores que llegados desde Burgos ejecutaron para la capital este monumento. La portada principal de la iglesia fue esculpida y proyectada en 1511 por Hernán Ruiz I, maestro mayor de la catedral (antigua mezquita del califato cordobés). Este frontal es el objetivo de la investigación y de los trabajos de restauración, que pusieron en valor este conjunto arquitectónico de la Córdoba del siglo XVI.
\end{abstract}

\section{PALABRAS CLAVE}

Convento Santa Marta, Hernán Ruiz I, Córdoba

\begin{abstract}
In the early days of the 12th century, the fall of the Muslim Empire and capture of Cordoba was taking place in the kingdoms of Spain. The process of Reconquista that began in the south-east of Andalucía, through the province of Jaen, and continued towards the most important city of the territories of Al Ándalus, Cordoba. A new period in art and history began, influenced by trends of the Kingdom of Castilla, already under the control of Christian kings. In the course of this new stage, a new architectural typology emerged in the city. It had religious purpose and are known as the palace-convents. One of the most important edifices is the Santa Marta convent along with its church, a landmark in late Gothic architecture. It owes such characteristics to families of stonemasons and sculptors who arrived from Burgos, making the city into this magnificent site. The main façade of the church was sculpted and designed in 1511 by Hernán Ruiz I, master of the cathedral (former mosque of the caliphate). This front is the subject of research and restoration work, which revalued this architectonical assortment of the Cordoba of the 16th century.
\end{abstract}

\section{KEYWORDS}

Santa Marta monastery, Hernán Ruiz I, Cordoba

${ }^{*}$ ) El presente informe forma parte de los estudios y procesos de intervención del convento de Clausura de Santa Marta de la ciudad de Córdoba, centrados en la portada de la iglesia conventual. Las actuaciones se desarrollaron durante tres meses aproximadamente, desde el 1 de febrero hasta el 30 de abril de 2009. Se trató de una obra adjudicada por Delegación Provincial de Córdoba de la Consejería de Cultura de la Junta de Andalucía a la empresa ARC, Sur, perteneciente al grupo BRIO, formado por las empresas ARC, Hidropresión y Tecnisan.

$\left.{ }^{(* *}\right)$ Licenciada y colegiada en Historia del Arte por la Facultad de Filosofía y Letras de la Universidad de Córdoba, con maestría en Gestión de Patrimonio desde el Municipio y especialización en Accesibilidad de Patrimonio Cultural. Técnico de Conservación y Restauración con especialidad en Bienes Muebles por el Instituto de Restauración del Maestrazgo, Teruel. Maestría en Restauración y Rehabilitación del Patrimonio por la Universidad de Alcalá de Henares, Madrid. Se ha desempeñado como directora técnica de conservación y restauración de la empresa ARC Sur, S. L. y como gerente de ADNOR y la iniciativa de turismo sostenible Paisajes Mineros de Jaén, programa de la Consejería de Turismo de la Junta de Andalucía, España. Contacto: wismolino@hotmail.es 


\section{Córdoba, la ciudad de las tres culturas, desde sus primeros asentamientos}

En el sur de la Península Ibérica (España), a 390 kilómetros de la capital, Madrid, está ubicada la ciudad de Córdoba, perteneciente a la comunidad autónoma de Andalucía. Enclavada en el valle del río Guadalquivir, entre Sierra Morena y la Campiña, la ciudad de Córdoba fue el último punto navegable, por lo que se constituyó desde la Antigüedad como un centro económico de crucial importancia tanto para las transacciones internas como externas.

La situación privilegiada, la riqueza del territorio y la fertilidad de su campiña propiciaron el establecimiento de los primeros asentamientos, de los que hay constancia gracias a los estudios de polen, semillas y fauna ejecutados por el Consejo Superior de Investigaciones Científicas (CSIC). En los núcleos de asentamiento los habitantes de la zona explotaban cultivos de cereal, vid y olivo silvestre o acebuche, hasta que en el siglo VIII a. C. los fenicios y griegos implantaran sus variedades domésticas en las cepas ya existentes en la provincia (Martín de la Cruz, 2003).

Estas tribus se establecieron en una de las zonas más altas de la orografía de la ciudad, a escasos 100 metros, dentro del actual parque Cruz Conde y zona de reserva arqueológica. Se trata de una colina o cerro artificial formado por la acumulación de los restos arqueológicos de los asentamientos primitivos. A esta reserva se la denomina Colina o Cerro de los Quemados (Jiménez Salvador \& Murillo Redondo, 2002).

Los estudios estratigráficos realizaron en 1973 por los arqueólogos Luzón y Ruíz Mata aportaron datos de los asentamientos desde el siglo $\mathrm{X}$ a. C., y establecieron la cronología de la Corduba prerromana. Esta investigación se vería luego perfilada por los trabajos arqueológicos de 1992, realizados por Juan F. Murillo Redondo y José L. Jiménez Salvador, que permitieron determinar, gracias a las evidencias de hábitat y cerámica campanéense, la existencia de un asentamiento estable desde finales del siglo III hasta el siglo I a. C.:

La ya demostrada continuidad en la ocupación del asentamiento turdetano y su coexistencia con la ciudad de Marcelo ayuda a comprender las razones de la rápida promoción de ésta dentro del nuevo orden implantado por Roma, al heredar el papel preeminente de su antecesora, cimentado en un cúmulo de factores económicos, políticos y estratégicos tejidos durante siglos. Del mismo modo, aclara de un modo definitivo la presencia de los "indígenas selectos" que formaron parte del núcleo fundacional, sin duda pertenecientes a la oligarquía turdetana de Corduba. En esta línea, resulta enormemente ilustrativo el que la nueva ciudad romana mantuviera el nombre de su antecesora, demostrando la pujanza del elemento local turdetano que veremos en otras manifestaciones de la cultura material. (Jiménez Salvador \& Murillo Redondo, 2002, p. 185)

En el periodo comprendido entre los años 156 y 152 a. C., con la llegada de las tropas del cónsul Marco Claudio Marcelo, los asentamientos turdetanos y la milicia romana pasaron a constituirse en una ciudad romana. Tras ser asolada por un terremoto y asediada en el siglo I por Julio César, la ciudad comenzó a ser reconstruida y años más tarde se convertiría en la capital de Beatica, lugar donde se cultivaron las ciencias, las leyes y las artes, cuna de filósofos y políticos como Séneca, uno de sus máximos representantes.

El siguiente proceso que transformó la historia y cultura cordobesa fue la llegada de los judíos. Según las crónicas, esta población llegó durante la época ibero-turdetana, y alcanzó su periodo de máximo esplendor económico, político y cultural durante el emirato y califato musulmán. Algunos de sus más destacados miembros formaron parte del gobierno Omeya como ministros de los monarcas, y muchos fueron médicos de afanado prestigio -como es el caso de Maimones-, sobresalientes orfebres y banqueros. Crearon academias, zocos y sinagogas, hasta que fueron expulsados en 1492 por los reyes católicos (Montenegro, 2016). 
Tras el decaimiento del Imperio romano la ciudad tomó de nuevo impulso y reanudó su expansión. Una nueva doctrina proliferó por todas sus latitudes: bajo la mirada de un nuevo panteón monoteísta, el dogma y la teología del cristianismo se expandieron entre todas las clases sociales. Durante el siglo IV se estableció en la ciudad la sede episcopal, con lo que aparecieron nuevas tipologías arquitectónicas de índole religiosa y civil. Se trata del pleno apogeo del arte paleocristiano, impulsado por el obispo Osio, que duró hasta el siglo VII, cuando la ciudad de Córdoba cayó bajo control musulmán (Gallegos, 2001). Corría el año 92 de la Hégira y el 711 del calendario cristiano cuando"los musulmanes al llegar se instalan en un marco urbano preexistente, como es la antigua urbe, que pasaran a reutilizar y rehacer" (Mazzoli-Guintard, 2001, p. 82).

La urbe islámica pasó a llamarse Qurtuba, y comenzó un desarrollo imparable que en aproximadamente siete años la convirtió en la capital de Al Ándalus, dependiente del califato de Damasco. La peripecia y voluntad de los califas de demostrar su grandeza llevaron a la dinastía de los Omeyas a organizar los territorios conquistados, dominar los espacios y continuar con la expansión (Mazzoli-Guintard, 2001).

El extraordinario desarrollo urbanístico, artístico, científico y comercial de la ciudad de Córdoba alcanzó su cima con la llegada de un joven sirio, que en el año 756 se proclamó emir de la ciudad: Abd al- Rahman I (Abderramán). Tras cinco años de diáspora, había conseguido escapar de la matanza que sufrió su familia, los Omeyas, en Damasco a manos de la familia rival, los Abbasíes, que se hicieron con el poder del califato. En el año 770 Abd al- Rahman I rompió la unidad política con Damasco, y proclamó al -Áldalus como emirato independiente y a Córdoba su capital, e importó desde Oriente un lenguaje arquitectónico propio: "Córdoba fue la sede del Estado omeya andalusí, un estado que se pretendía unitario y centralista. Su mezquita aljama fue su mayor representación arquitectónica" (Souto, 2009, p. 17) (Figuras 1.1 y 1.2).

Aproximadamente 30 años más tarde, según recogen las crónicas de la época, se comenzó a construir la mezquita-aljama mediante la reutilización de elementos romanos y visigodos fruto del expolio (Pérez Higuera, 2001), base sobre la que hoy en día se asienta la catedral de la cuidad. Más de dos siglos mantuvo la supremacía Omeya el poder, hasta que el catolicismo llegó a la ciudad de la mano de los reyes de Castilla, evento descrito por un cronista cristiano, quien señala que la ciudad fue conquistada el día de San Pedro y San Pablo por el Rey Fernando III el Santo: “Acaecía el año 1236 de nuestra era en la capital del califato, llena de peculiar esplendor y riqueza, cuando de repente empezaron a tañer los sones de las campanas anunciando la entrada a la ciudad, por el puente de San Rafael, del rey seguido de sus barones" (Marfil Ruiz, 2001, p. 149).

Tras la reconquista se produjo un cambio de la estructura sociopolítica y religiosa de la ciudad, y sus construcciones más emblemáticas fueron las primeras en sufrir los cambios radicales en su tipología.

\section{Contexto histórico artístico del monasterio de clausura}

Como ocurre con otras clausuras cordobesas, el convento de Santa Marta está ubicado en el barrio o collación de la Axerquía, área que corresponde a la antigua ciudad baja de Córdoba, la cual junto a la Medina conformaba la ciudad árabe (Benítez, 2011). Tras la conquista de la ciudad, en el entramado urbano surgen importantes construcciones y tipologías arquitectónicas cristianas, como iglesias, conventos y monasterios (Figura 2).

El monasterio se remonta al siglo XV, cuando se estableció un beaterío en la Casa Corral de los Cárdenas, donada en 1459. Fue convertido en convento en 1466 por medio de la bula del Papa Paulo II. Posteriormente, en 1468, se anexionó la Casa del Agua, antiguo palacete mudéjar del que todavía hoy se pueden apreciar algunas de sus yeserías, propiedad de Doña María de Carrillo, hija del conde de Cabra (Benítez, 2011). 
devenir Vol. 4, N7, ENERO- JUNIO 2017, PP. 11-28 - EstudIOS | ISSN 2312-7562

UNIVERSIDAD NACIONAL DE INGENIERÍA, LIMA

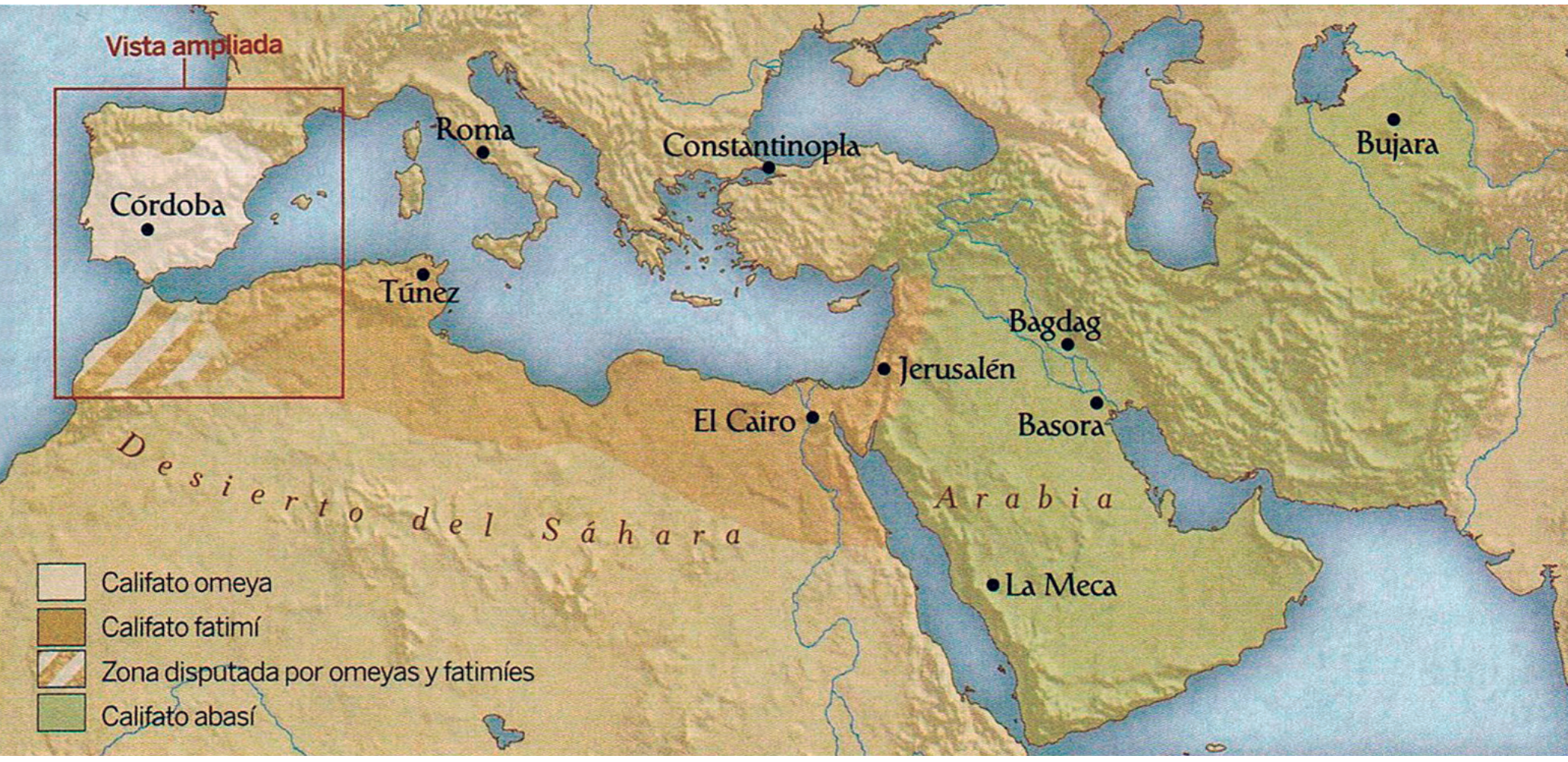

Figura 1.1. Distribución de los califatos

Fuente: National Geographic, 2008, 53, p. 85.

Figura 1.2. Disposición de los Reinos de España

Fuente: National Geographic, 2008, 53, p. 90 .

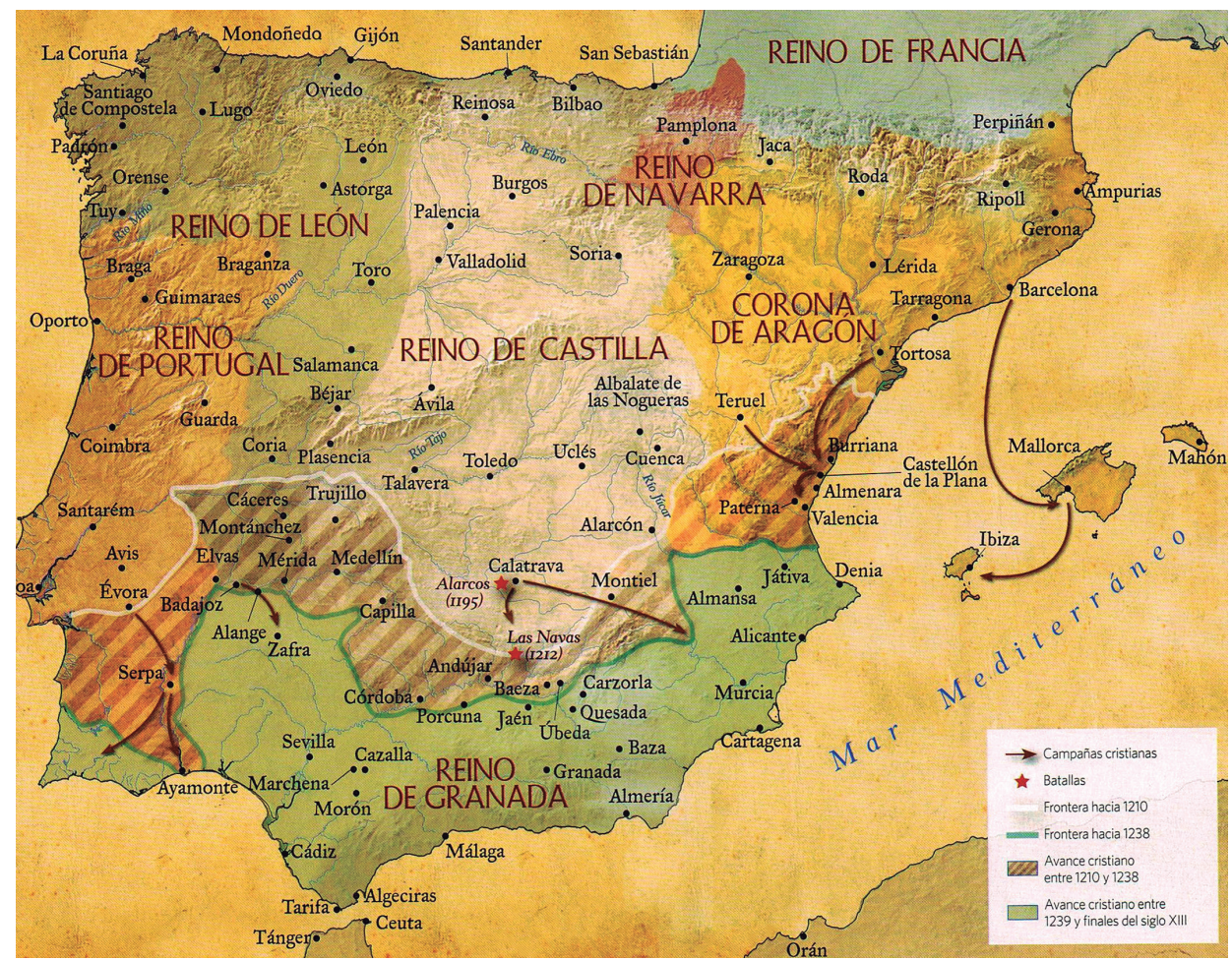




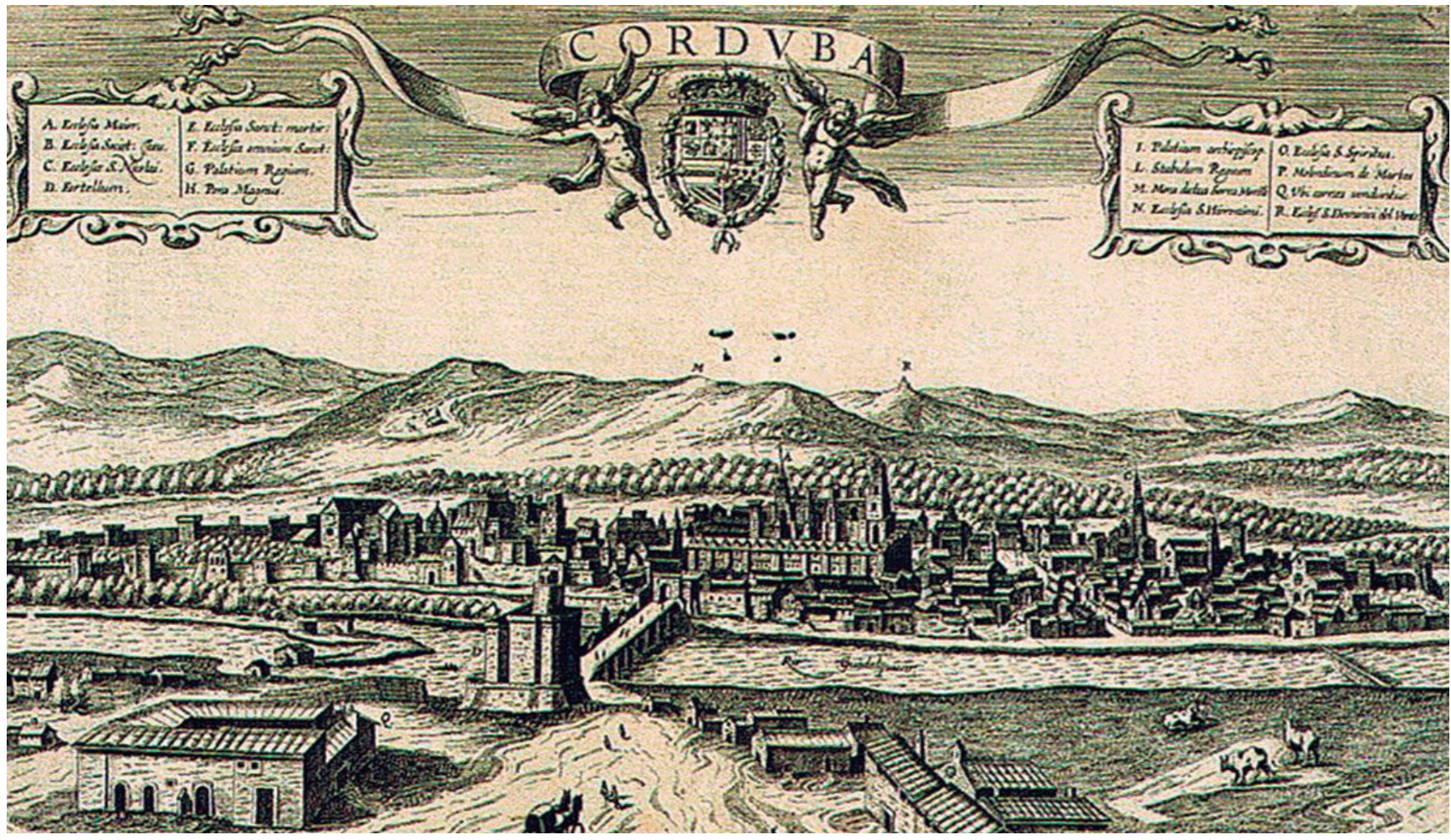

La tipología arquitectónica de casas-palacios convertidas en conventos es importante porque

Los conventos de religiosas pertenecientes a la Edad Media en Córdoba fueron fundados gracias a la donación de casas nobiliarias. Este hecho condicionó la planta de los conventos, cuya arquitectura, heredera de la civil, aunque funcionalmente religiosa, quedó irremediablemente ligada a la fisonomía de los palacios de entonces, influida por el gusto mudéjar. Este último aspecto es notorio, fundamentalmente, en el convento de Santa Marta. (Jordano Barbudo, 1996 p. 234)

La distribución del convento se articula en torno a varios claustros, cinco principales y cuatro menores - uno de ellos el huerto conocido como Santa Inés-, al igual que ocurre en otros conventos femeninos de la ciudad durante el siglo XV, como puede atestiguarse en el monasterio de San Rafael, de las madres capuchinas. La importancia de este conjunto de conventos, con un trazado laberíntico, reside en que en ellos pervive la arquitectura civil posterior a la conquista cristiana de Córdoba, que a su vez es heredera de la hispano-musulmana. Esto puede observarse en la sucesión de patios, algunos de los cuales aún conservan la fuente a ras de suelo (Jordano Barbudo, 1996) (Figura 3).

El claustro principal es conocido como el del cinamomo, debido al árbol que alberga en una de sus esquinas. De acceso restringido por encontrase en la zona de clausura del convento, presenta doble altura y galerías, así como restos de las yeserías originales del palacio, algunas de las columnas originales, capiteles de acarreo $^{1}$ y una fuente remodelada en el s. XVII (Benítez, 2011). Entorno a este claustro están dispuestas el resto de dependencias y salas propias de las funciones de un convento: las celdas, el refectorio, la cocina, la sala capitular, la enfermería y la iglesia.
Figura 2. Córdoba. Grabado anónimo del siglo XVI

Fuente: El esplendor de los Omeyas ( $\mathrm{p}$ 84), por C. Mazzoli-Guintard, 2001 Córdoba, España: Junta de Andalucía, Consejería de Cultura - Fundación El Legado Andalusí. 


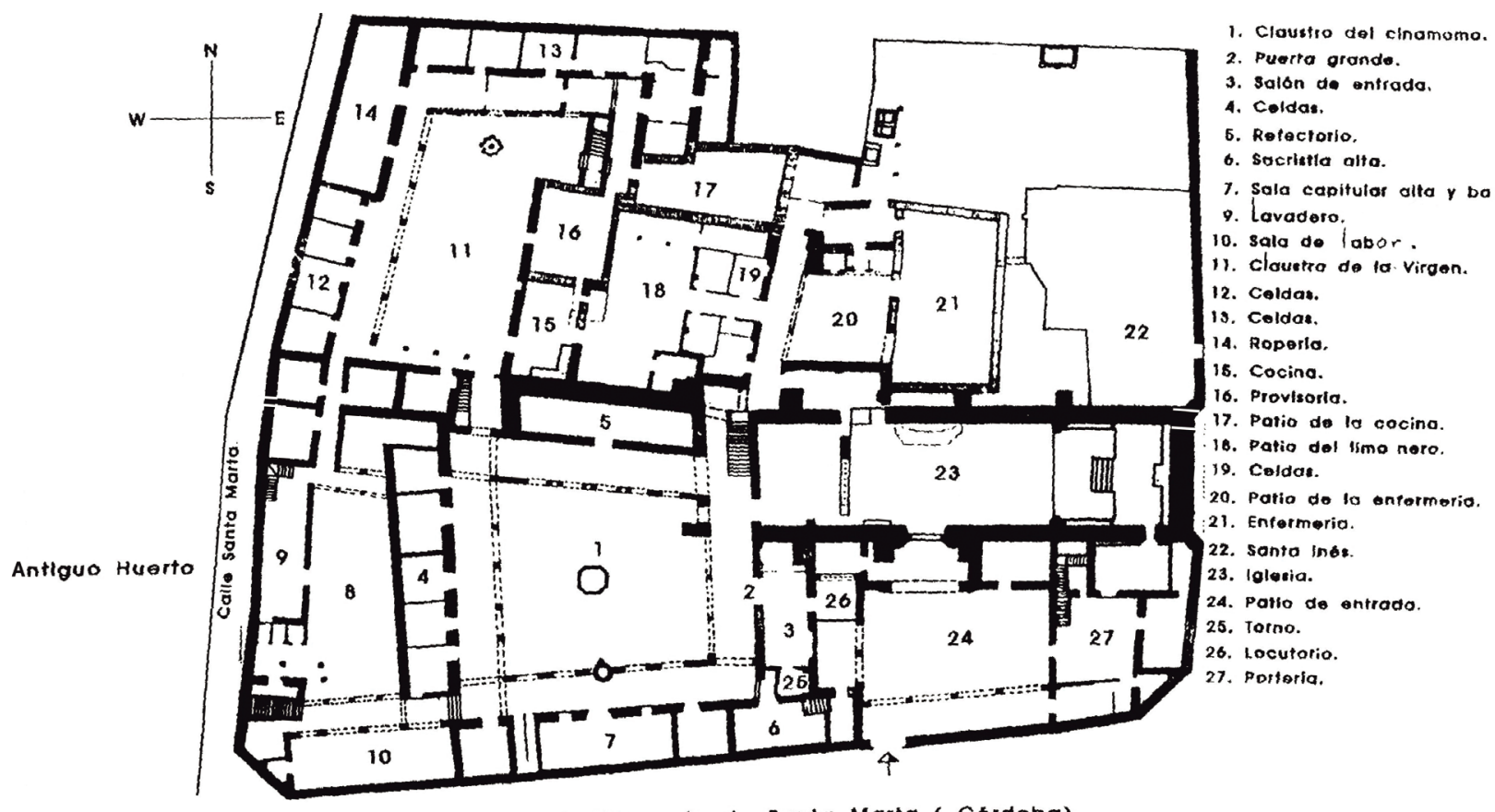

Fig. 2. Convento de Santa Marta (Cordoba).

Arquttecto: J. A. Gomez-Luengo.

Figura 3. Plano del monasterio Fuente: Arquitectura Medieval Cristiana de Córdoba (p. 193), por M. A. Jordano Barbudo, 1993. Madrid, España: Universidad Complutense de Madrid.
En el templo se encuentra la factura de una de las primeras intervenciones de la familia de canteros que más trabajó en la ciudad desde finales del siglo XV y principios del siglo XVI, los Hernán Ruiz. Es muy probable que Gonzalo Rodríguez, padre del clan, iniciara las obras de la iglesia conventual, la cual tiene claros vínculos con otros edificios del momento, como el monasterio de San Jerónimo de Valparaíso, la portada de San Andrés y la capilla del hospital de San Sebastián (Jordano Barbudo, 1996). Hernán Ruiz era durante esos años uno de los artistas de referencia de la provincia: desde 1502 hasta 1547 ostentó el cargo de maestro mayor de la catedral de Córdoba, donde desarrolló una estética gótica en sus obras, a las que a modo de pinceladas fue introduciendo el estilo renacentista que poco a poco llegaba desde Italia.

Las primeras piedras del templo fueron colocadas alrededor de 1479 por Gonzalo Rodríguez, padre de Hernán Ruiz l, quien continuaría con la obra tras la muerte de su padre. Su obra culminó con la portada principal, realizada el primer tercio del siglo XVI, hacia el año 1511 (De la Banda y Vargas, 1974). Estilísticamente, el templo se sitúa en el tránsito del último gótico al primer Renacimiento. Es de planta basilical, y consta de una sola nave cubierta con bóvedas de crucería, capilla mayor, y coro alto y bajo a los pies. La capilla mayor está cubierta con una bóveda de terceletes, y el coro alto y bajo con aljarfes. El coro alto fue sustituido por una bóveda de escayola, de acuerdo a los modelos de la nave central (Jordano Barbudo, 1996). La nave no cuenta con más adorno que las nervaduras de las bóvedas y los perfiles de los vanos, que al exterior se presentan abocinados, ejecutados en piedra caliza de la provincia. El resto está totalmente encalado. Es elegante y sencilla, y contrasta con los gustos del periodo musulmán, cuando la arquitectura estaba dominada por el horror vacui.

La historia del convento de Santa Marta de la ciudad de Córdoba constituye un episodio importantísimo del apogeo arquitectónico del siglo XVI, conocido como gótico humanista. Este bien inmueble, de indudable valor artístico, es propiedad del Obispado de Córdoba, y fue declarado el 21 de marzo de 1980 monumento BIC (Bien de 


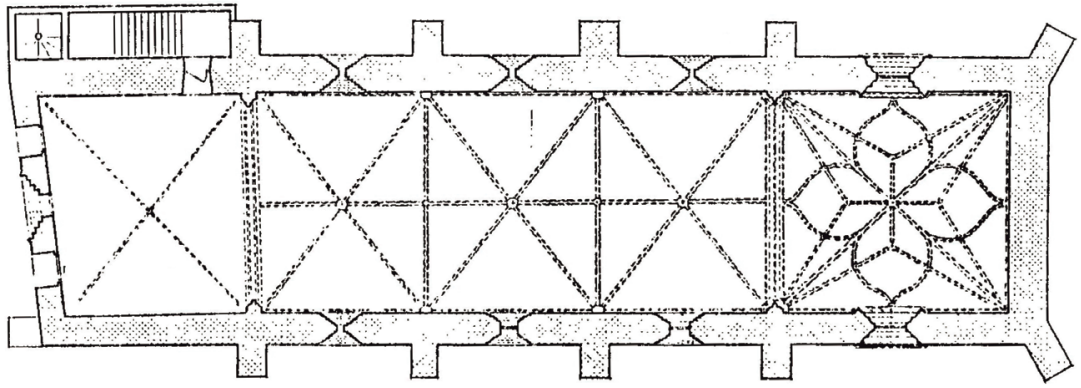

PLANTA ALTA

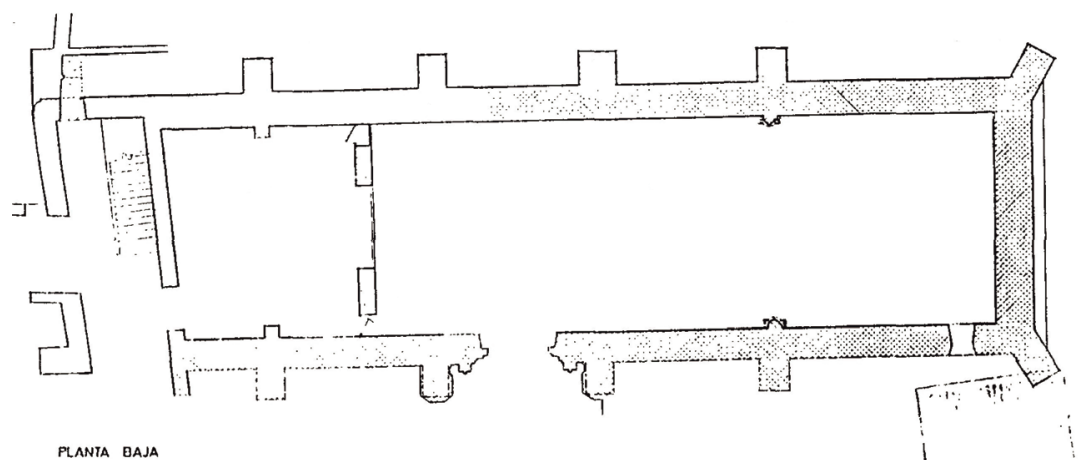

Interés Cultural), figura de máxima protección entre los Bienes Catalogados e Inventariados de la Junta de Andalucía² (Figura 4).

\section{La portada. Aspectos estilísticos}

El acceso a la iglesia desde la calle es a través de una puerta de grandes dimensiones, flanqueada por un alto muro sin exorno alguno, íntegramente encalado, que desemboca en el atrio de la entrada, uno de los dos patios de acceso público al convento de clausura, con la entrada y lateral izquierdo porticado. Desde el atrio se puede entrever solo parcialmente la portada principal; para observarla es necesario atravesar el arco de medio punto, totalmente encalado, que da acceso a la iglesia. Este es el único acceso público de la iglesia, que está localizado en el muro sur, en el lado de la Epístola. En el lateral izquierdo de la portada se encuentra un habitáculo que en la actualidad hace las veces de locutorio, y torno o punto de venta de los productos de las monjas de clausura, el cual esta retranqueado de la línea del muro de acceso a la portada.

Entre el espacio del arco y el frontis se dispuso una cubierta ligeramente inclinada que cumple la función de alero; desaloja el agua de lluvia y protege la portada. Está formado por once vigas o estribos de distinta sección e idéntica separación, y cubierta al exterior con teja islámica. En época gótica, la separación y colocación del maderamen se denominaba tant plein que vide, y pasó a llamarse en épocas más tardías en España a calle y a cuerda. La carpintería por la que se ha optado en las calles es una de las soluciones más comunes, denominadas a cinta y saetino, que responde a la necesidad de cubrir sobremanera la unión de la tablazón, y evitar la caída del relleno del forjado una vez seco y disgregado. Toda la estructura y elementos del maderamen fueron realizados con madera de pino (Matuco, 2003).

2. Instituto Andaluz de Patrimonio Histórico. Consejería de Cultura. Catálogo de Patrimonio Inmueble de Andalucía.
Figura 4. Plantas de la Iglesia

Fuente: Arquitectura Medieval Cristiana de Córdoba ((p. 194), por M. A. Jordano Barbudo, 1993. Madrid, España: Universidad Complutense de Madrid. 
El frontis lo perfila un arco deprimido, formado por numerosos baquetones que arrancan desde el zócalo y se entrelazan elegantemente a modo de alfiz. Los baquetones sostienen sutilmente la cornisa de escaso desarrollo, la cual divide el frontis en dos cuerpos. Cuatro de estos estilizados baquetones cumplen una doble función: la de columnillas apoyadas en un plinto de escaso desarrollo, rematadas por un capitel con decoración vegetal que ya ha perdido las formas clásicas, así como la de enmarcar los arcos a modo de cordoncillos. Les preceden otros dos capiteles con una ingeniosa solución técnica y tipológica, ya que también hacen de plintos. Tienen decoración vegetal pero están sujetos por unas esculturas, casi de bulto redondo, que a modo de ménsulas figuradas sostienen el arranque del arco. En ambos lados de la puerta se localizan dos pilares arquitrabados y cajeados, enaltecidos con una columna de fuste liso, y capitel con decoración vegetal que se entrelaza a modo de panel de abejas, rematado por un arco conopial. Los pilares continúan su desarrollo en el segundo cuerpo como pináculos rematados con un chapitel de decoración vegetal (hojas de berza) y florida muy estilizada.

El segundo cuerpo está articulado por varios arcos ojivales que encuentran su desarrollo en los baquetones que ascienden desde el primer cuerpo. En el interior se desarrolla un arco conopial que se entrelaza, y crea la decoración aspada del gablete superior, culminado por decoración vegetal de la que emerge la cabeza de un angelote. El último de los arcos ojivales y de mayor desarrollo está rematado por el mencionado gablete, del que se sostienen dos músicos con cabello de prominentes rizos, que discurren por sus cuerpos a modo de vestimenta. El interior de los arcos cobija decoración formada con elementos arquitectónicos como arcos conopiales y trebolados. El resto de la decoración que se articula en este segundo cuerpo es también de carácter arquitectónico, compuesto por arcos geminados conopiales y arcos de herradura distribuidos en dos arcadas.

El mayor desarrollo creativo y uno de los elementos decorativos más importantes, desde el punto de vista artístico, son los relieves ubicados en la arquivolta del tímpano, donde se alternan a modo de guirnalda escenas de la recolección de la vid, hojas de parra, una serpiente, un animal mitológico -figura que a pesar del elevado grado de erosión puede intuirse que posee patas y cabeza de dragón-y dos copas que a modo de cáliz hacen de inicio y final de las escenas representadas. Por último, las esculturas que se localizan en las esquinas de los pináculos son dos hombres tortuga, símbolos de la contemplación, el sosiego y la meditación.

La puerta o portón de acceso a la iglesia es de doble hoja, cuenta con puertas interiores, es de madera de nogal, y está cubierta por franjas horizontales y verticales de clavos con cabeza polilobulada. Se trata de una puerta provista de cuatro falsas bisagras y cuatro bocallaves.

La belleza y grado de perfeccionamiento alcanzado en la portada por Hernán Ruíz son tan elevados que fusionan todos los elementos decorativos y arquitectónicos medievales con la sutileza, el equilibrio y la sobriedad propia del más clásico Renacimiento, y de los gustos importados de la escultura burgalesa.

\section{El proceso de intervención}

La información y documentación que se recopiló durante el proceso de investigación del inmueble fue amplia, aunque escasa en lo referente al objeto específico de este estudio, la portada principal de la iglesia. Tras consultar a algunos de los más prestigiosos historiadores de la ciudad, y realizar una exhaustiva investigación de la documentación escrita, no se encontró ningún testimonio fotográfico o dibujo relevante de la portada en el que se muestren las trazas originales de esta obra. Solo existe un testimonio pétreo frente a la fachada oriental de la mezquita-catedral, la fachada de la capilla del antiguo hospital de San Sebastián, que actualmente forma parte del Palacio de Congresos y Exposiciones. Presenta un grado elevado de erosión y pérdida de material que dificulta su lectura, así como la realización de cualquier estudio comparativo entre ambas obras. 
En 1984 la UNESCO declaró la mezquita-catedral Patrimonio de la Humanidad. Más tarde, en 1994, esta denominación se amplió al centro histórico, debido a la gran riqueza monumental de los vestigios de la época romana, árabe y cristiana aún conservados. Dentro del nuevo perímetro quedó incluido el convento. El monasterio y la iglesia de Santa Marta en la actualidad están localizados en la calle del mismo nombre, número 10. El convento es el más antiguo de los 23 monasterios de clausura de la diócesis de la provincia de Córdoba y el segundo más antiguo de la orden de monjas jerónimas en España.

La puesta en valor del convento y los procesos de intervención estuvieron coordinados por la dirección Facultativa de la Delegación Provincial de Córdoba de la Consejería de Cultura de la Junta de Andalucía, y el equipo fue conformado por Marina Ruíz Gutiérrez, restauradora conservadora de la Junta de Andalucía y Antonio Paniagua, arquitecto conservador de la Junta de Andalucía.

La empresa ejecutora fue Arte Restauración y Conservación Sur S. L., perteneciente al grupo BRIO, formado por las empresas ARC, Hidropresión y Tecnisan. Los trabajos fueron realizados por un equipo multidisciplinar conformado por titulados en Conservación y Restauración de Bienes Culturales, historiadores y arquitectos técnicos. Así mismo, colaboraron otros especialistas, entre ellos un maestro artesano. Todos ellos trabajaron bajo la dirección técnica de ARC Sur.

El proceso de restauración se desarrolló a lo largo de tres meses, desde el 1 de febrero hasta el 30 de abril de 2009. Los trabajos fueron coordinados por Noema Wis Molino en la dirección técnica. Las pautas de actuación fueron siempre consensuadas y aceptadas por la dirección, después de profundos análisis y estudios de la documentación existente, y de la propia lectura de la obra.

\section{Criterios de intervención en bienes culturales}

Los criterios nacionales que determinan cómo se realiza una intervención en las obras de arte son los mismos que se emplean en el ámbito internacional, que han sido debatidos, aceptados y están vigentes actualmente en las distintas cartas de restauración.

La obra, considerada un objeto único realizado por un artista determinado en un momento preciso, es única e irrepetible, y son esas cualidades las que condicionan la metodología de trabajo y los criterios que se adoptan. Este respeto hacia la obra de arte se tomó como premisa para determinar los criterios de intervención:

- La justificación de la necesidad de la intervención de acuerdo al estado de conservación, nunca según meros principios estéticos

- Identificación y eliminación los factores de deterioro del Bien Cultural con el fin de evitar o disminuir el proceso de degradación la obra

- La conservación de la obra y respeto del original, respondiendo a la doble polaridad de sus aspectos histórico y estético. Todo tipo de testimonio pasado, siempre y cuando no interfiera en su conservación, debe sobrevivir el máximo tiempo posible.

- La durabilidad en el tiempo

- Inalterabilidad de todos sus componentes

- La reversibilidad de los materiales empleados en los procesos de intervención

- La intervención con materiales discernibles que sean fácilmente diferenciables y se circunscriban a los márgenes de las pérdidas

- La utilización de materiales con caracteres físico-químicos compatibles y análogos con el original, siendo su uso justificado y experimentado en el tiempo

- La restitución de la unidad potencial de la obra dentro de las limitaciones dictadas por el estado de conservación de la obra (Rivera Blanco, 2001) 


\section{Estado de conservación material}

\section{Piedra}

En un primer momento el reconocimiento de la obra se realizó mediante análisis visual y documentación fotográfica. Antes de comenzar con la restauración se realizó una caracterización mediante el análisis del tipo de roca en el que se iban a realizar los tratamientos físicos, mecánicos y químicos.

La portada del convento de Santa Marta está realizada íntegramente en roca sedimentaria, cuya característica principal es la presencia de fósiles, laminación, estratificación y minerales. En concreto, se trata de una caliza carbonática fosilífera, compuesta por bioclastos, de color amarillento, porosidad elevada y dureza media. Todas las uniones que se pueden apreciar están tomadas con mortero de cal y arena de diversa granulometría, libre de cementos. Es un mortero bastante compacto y denso (excepto en las zonas donde se han producido las lesiones), de color grisáceo. Presenta gran porosidad al entrar en contacto con agua destilada, y físicamente tiene una dureza media ${ }^{3}$.

El estado de conservación de la obra puede calificarse de bueno ${ }^{4}$, ello gracias a las continuas labores de mantenimiento realizadas por las hermanas de la congregación. Las intervenciones históricas han sido periódicas y de carácter profundo particularmente en la zona de zócalo, donde se han efectuado reconstrucciones volumétricas. También se han llevado a cabo intervenciones parciales, como la policromía de los sillares y las diarias labores de limpieza de excrementos en las zonas de fácil acceso.

En una primera observación de la obra es posible apreciar diferentes tonalidades: las grisáceas, correspondientes a escorrentías o zona de lavado; restos de cal, producto de una intervención histórica realizada con cepillos metálicos; y pátinas de oxalatos de tonalidad oscilante entre ocres, anaranjados y rojizo-pardo, fuertemente adheridas a la epidermis de la piedra. Estas pátinas están formadas principalmente por whewelita (oxalato de calcio monohidrato) y wedelita (oxalato de calcio bihidrato).

Las lesiones más graves afectan desde el suelo al primer nivel de la cornisa. Estos soportes pétreos, tanto lisos como con relieves, presentaban alteraciones medioambientales, físico-químicas y antrópicas, las cuales se detallan a continuación.

\section{Alteraciones medioambientales}

El factor que más ha contribuido al deterioro de la fachada es la presencia de agua de Iluvia filtrada por el forjado, y del agua de la manguera utilizada para la limpieza diaria del suelo. El agua circula libremente, arrastrando depósitos de suciedad, excrementos de aves, sales, tierra, y las mismas partículas y capas superficiales de la piedra. Los depósitos que traslada el agua se depositan en los sillares, donde sirven como fuente de nutrientes que permiten el desarrollo de musgos y líquenes.

Además de la presencia del agua en estado líquido, resulta evidente la constante humedad en el paramento. El nivel freático en la ciudad es bastante alto, por la presencia de numerosos acuíferos en el subsuelo, provenientes del río Guadalquivir, que se encuentra a menos de 1 kilómetro. Esta humedad sube por los paramentos mediante capilaridad, hasta que poco a poco va traspirando a través de los sillares. 


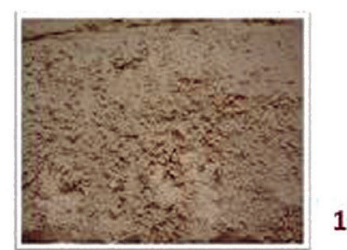

1
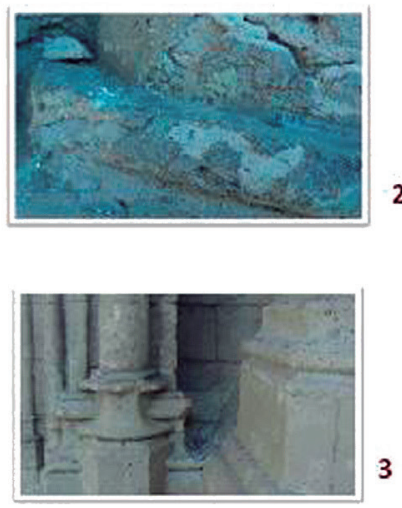

PIE DE FOTO

\section{LATERAL DERCH.}

1. AMPOLLAS Y ALVEOLOS

2. FISURAS Y DESPLACACIÓN

3. DEPÓSITOS DE EXCREMENTOS

4- MORTERO DE CEMENTO

5. ESMALTES SINTÉTICOS
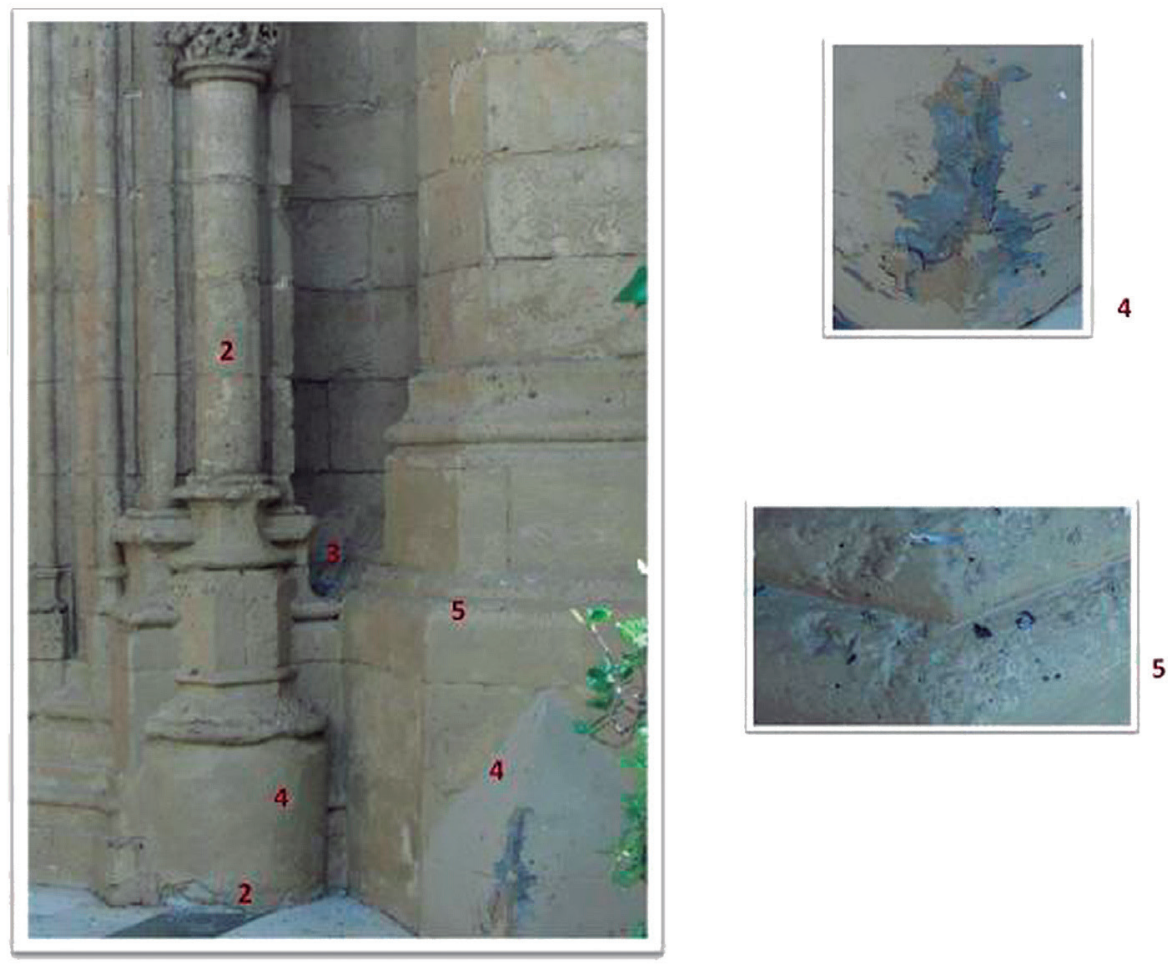

CONVENTO SANTA MARTA CÓRDOBA. PLANO: DETALLES DE ALTERACIONES

\section{Alteraciones físico-químicas}

Las alteraciones físico-químicas ligadas a los factores medioambientales y antrópicos son la desplacación, arenización, la aparición de fisuras y grietas, la alveolización y la dilución de macropartículas que por acción mecánica son arrastradas o eliminadas.

La desplacación y la alveolización se producen generalmente por tres motivos: la cristalización de sales, la gelifracción y la diferencia de tensiones entre materiales. En cuanto a la cristalización de sales, este fenómeno no puede observarse actualmente; sin embargo, es posible que haya sido la patología inicial que causó la pérdida de volumen en el zócalo, que en algunos puntos ha alcanzado los 50 centímetros de piedra. La gelifracción no alcanza cotas lo suficientemente altas para producir deterioro de forma sistemática. Por otro lado, la desplacación observada es fundamentalmente producida por las diferentes tensiones y grado de dureza de los materiales constructivos, el cemento Portland y los sillares pétreos, lo cual da lugar a la aparición de fisuraciones, desplacaciones, pérdida de material y arenización.

\section{Alteraciones antrópicas}

Las alteraciones antrópicas son las que más huella han dejado sobre el zócalo, tanto desde el punto de vista estructural como del estético. Las más frecuentes son la colocación de cartelería, el mantenimiento de los zócalos mediante la aplicación de cemento Portland, las posteriores policromías realizadas con esmaltes sintéticos y la limpieza mecánica con elementos abrasivos (Figuras 5 y 6 ).
Figura 5. Detalles de alteraciones Fuente: Elaboración propia, 2009. 


\section{Puerta de acceso}

La cara expuesta de la puerta de madera presenta principalmente deterioros de tipo antrópico: restos de papel adhesivo empleado para ubicar la cartelería y dos pequeños orificios de chinchetas utilizadas para el mismo fin. Además, su superficie se encontraba recubierta con varias capas de barniz sintético, tanto la madera como las cabezas metálicas de los clavos de fijación. También se observaron puntuales depósitos de excremento de ave.

El estado de conservación estructural de la madera es óptimo en la cara exterior, en la interior y en el núcleo, así como el de los elementos metálicos. La puerta no presenta ninguna falta de material, ataques de xilófagos, pudrición, u oxidaciones en la caña o cuerpo de la clavazón.

\section{Cubierta}

En un primer análisis se comprobó que todo el maderamen que componía la cubierta se encontraba estable. Es decir, no presentaba ataques de xilófagos, hongos, o daños estructurales. Sin embargo, existe constancia que en 1988 se realizaron trabajos de consolidación y refuerzo en diferentes puntos del inmueble, labores constatables en la cuarta, octava y novena viga que presentan bridas de forja (Jordano Barbudo, 1996).

A esta información se puede sumar la brindada por la actual madre abadesa (Sor María de Fátima), quien indicó que además se habían realizado trabajos puntuales en aquellas las tejas que habían sido movidas por las palomas y generaban filtraciones (comunicación personal, 2009). Así mismo, se detectaron algunas alteraciones menores medioambientales tales como filtraciones, escorrentías y depósitos de excrementos; y fisicoquímicas, producidas por la tinción de la tablazón con el mortero de cal del forjado.

\section{Procesos de restauración}

Los trabajos de intervención realizados sobre los paramentos pétreos se articularon en tres etapas: limpieza, reconstrucción volumétrica, y consolidación e hidrofugación.

El frontis de la portada estuvo encalado durante varios años, como lo demuestra la superposición de capas de este material. Hasta el momento no se ha encontrado documentación que indique el periodo en que se realizó este enlucido, es decir, si fue en el momento de su creación o corresponde a una modificación estética posterior. Tampoco hay constancia de la época en el que este mortero se eliminó de forma parcial, lo cual dejó la fachada como la vemos hoy, con la superficie de la piedra expuesta.

\section{Limpieza}

La primera acción fue una limpieza llevada a cabo con agua destilada, y un suave aspirado de todo el paramento, destinado a eliminar restos de la antigua red anti-paloma, la suciedad superficial y adherida como detritos de paloma, nidos de avispa, etc.

Debido a la profusión irregular de los restos de cal, el método elegido para llevar a cabo la limpieza fue la proyección de abrasímetro. Se eligió uno de dureza media, compuesto por silicato de aluminio y esferas de vidrio. La proyección se realizó empleando 2 bares de presión, sobre piedra seca. De esta forma el abrasímetro preservó la textura original de la piedra y eliminó solo las capas de cal.

Previamente a los tratamientos estructurales o reintegraciones volumétricas, se procedió a la aplicación de un tratamiento contra ataques biológicos. Para elegir el biocida adecuado se tuvo en cuenta una serie de exigencias: que no tuviese efecto corrosivo sobre la superficie pétrea, que no dejase residuos aceitosos, que no produjese cambios de coloración en la superficie y que fuese biodegradable. Así, se optó por la aplicación de un biocida no iónico, el cual fue aplicado por impregnación, con brocha. Tras su aplicación y período de actuación se neutralizó con agua desionizada. 


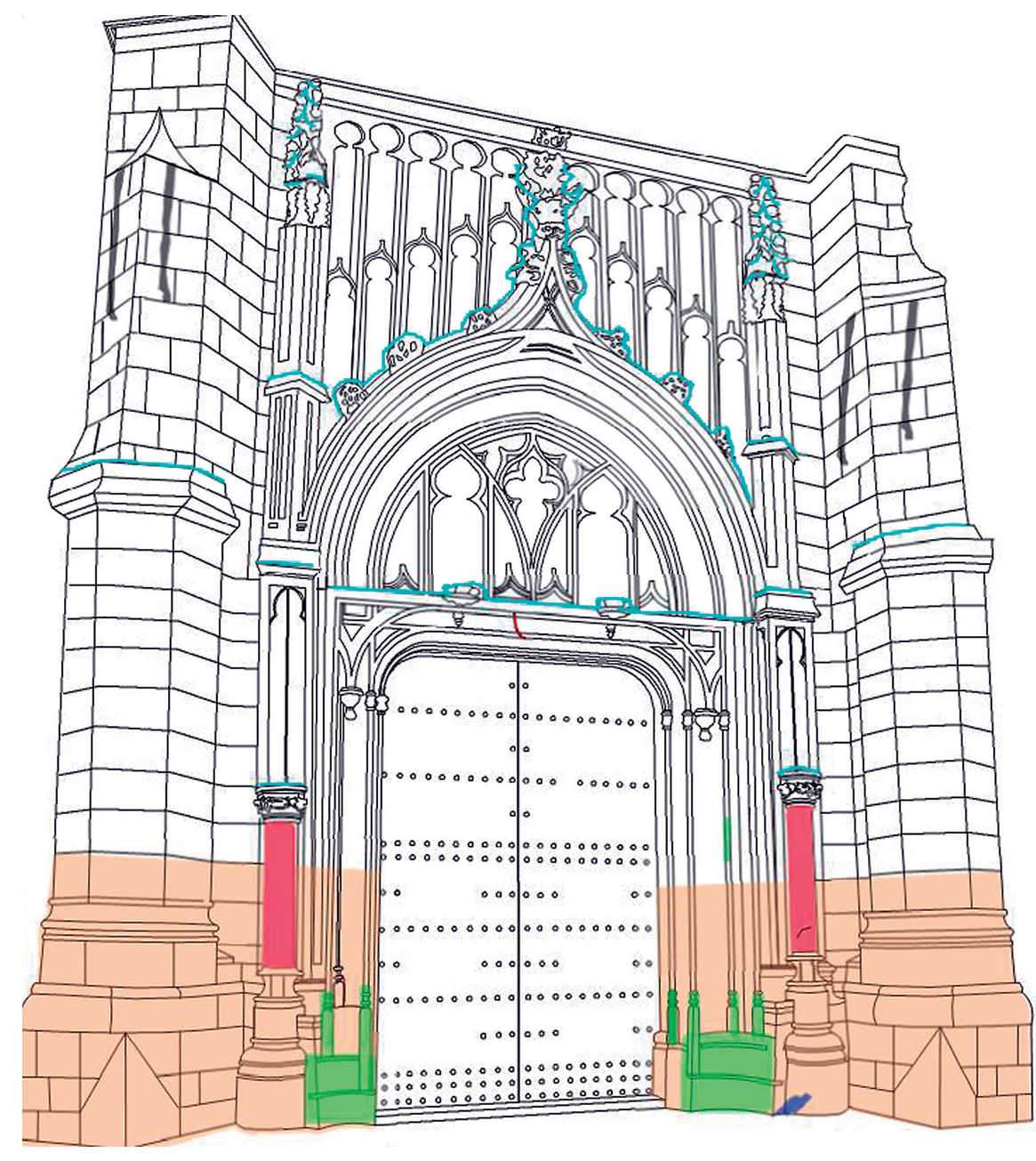

\section{Reconstrucción y consolidación volumétrica}

El proceso se inició eliminando los añadidos de morteros de cemento y cal mediante picado manual. Luego se comenzó la reconstrucción destinada a devolverle a la fachada su integridad formal y estética, lo cual dota a la obra de un carácter artístico e histórico.

El zócalo presentaba, tal como se indicó previamente, una serie de lesiones: fisuras, falta de material, alvéolos y añadidos. La reconstrucción se realizó empleando un mortero de restauración de marca Parrot, de la misma tonalidad que la piedra. Este mortero está libre de sales, y su dureza una vez finalizado el proceso de secado es menor que el de la piedra original, factor decisivo para eliminar las diferentes tensiones superficiales y la consiguiente fisuración.

La reconstrucción del zócalo se realizó hasta alcanzar un volumen de 50 centímetros. La falta de material original era considerable: algunos volúmenes y molduras se habían perdido totalmente. Para realizar los recrecidos se tomó como patrón los morteros de cemento superpuestos, debido a la ausencia de documentación histórica que indique el diseño original de la obra. Una vez reconstruidos los volúmenes de los sillares, baquetones, columnas y rejuntados se nivelaron y texturaron con una bujarda para simular la textura de los sillares. La textura resultante no es totalmente mimética, sino fácilmente reconocible.

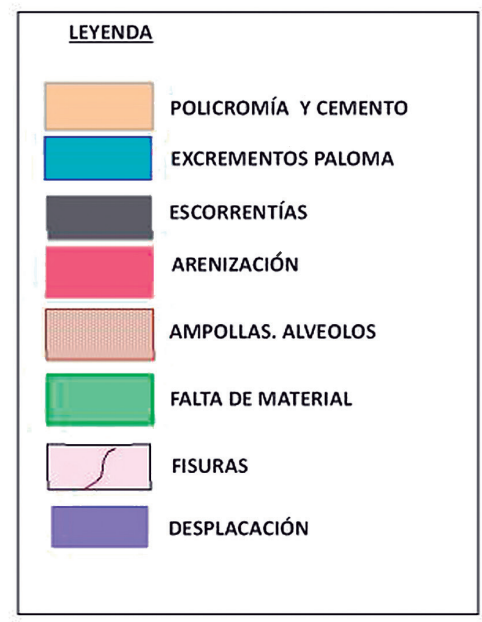

CONVENTO SANTA MARTA CÓRDOBA PLANO: MAPEADO DE ALTERACIONES

Figura 6. Mapeado de alteraciones Fuente: Elaboración propia, 2009. 
El resto de molduras, sillares y relieves distribuidos en los paramentos presenta una pérdida de material puntual, la cual no dificulta la lectura integral y unidad estética, por lo que se optó por la no intervención.

\section{Rejuntado de sillares}

Todas las juntas de los sillares que se encontraban en un estado avanzado de disgregación se eliminaron, y tras el saneado se procedió al nuevo rejuntado de los sillares con mortero de sacrificio. Se optó por este tipo mortero debido a sus propiedades físico-químicas, óptimas con respecto a los sillares. Ya que tiene mayor elasticidad y menor dureza que los paramentos pétreos, evita que las tensiones se extrapolen a los sillares, lo cual ocasionaría la aparición de nuevas fisuras, desplacados o pérdida de material en los paramentos pétreos, donde se encuentra el valor histórico artístico.

\section{Integración cromática}

Finalizado el tiempo de secado y fraguado de los morteros, se procedió a llevar a cabo la integración cromática. Como se ha mencionado con anterioridad, el mortero utilizado era de una tonalidad similar a la piedra; sin embargo, fue necesario integrar cromáticamente algunas zonas.

La integración se efectúo utilizando tierras y pigmentos naturales en diversos tonos, aglutinadas en medio acuoso. Los pigmentos se aplicaron con brocha y se optó por realizar un estarcido sutil en aquellas zonas donde era necesario.

\section{Consolidación e hidrofugación de elementos pétreos}

Tras la finalización de los texturados, el rejuntado de sillares y la integración cromática, el siguiente paso fue la aplicación del consolidante. Este es uno de los aspectos más controvertidos de la restauración de elementos pétreos: la aplicación de un consolidante idóneo según la composición mineralógica del material pétreo (Alcalde, Villegas \& Martín, 2000).

Se aplicó consolidante en los paramentos pétreos del segundo cuerpo para evitar la evolución de los procesos de arenización, erosión y alveolización futuras. En esta ocasión se eligió un consolidante comercializado con el nombre silicato de etilo. Se aplicó en baja concentración para asegurar la granulometría de la piedra sin saturar el poro: así se mantiene la permeabilidad del soporte al vapor de agua. Una vez aplicado el consolidante se pudo comprobar que el material pétreo no sufrió variación en el índice de refracción.

Por último, se aplicó con brocha un hidrofugante e hidrorepelente ${ }^{5}$ en la zona del zócalo para evitar las futuras alteraciones.

\section{Puerta y cubierta}

En el caso de la techumbre, el primer paso fue la eliminación de la antigua red anti-palomas, que estaba totalmente desintegrada y con el cuerpo de algunas, que habían quedado atrapadas años atrás. Posteriormente se procedió al sellado de todos los clavos que decoran la puerta, para evitar la erosión una vez comenzados los trabajos de proyección de abrasímetro. Tanto en la puerta como en la techumbre se eliminaron los barnices con la proyección de abrasímetro, de silicato de aluminio, con una presión que oscilaba entre 1 y 2 bares. Los restos de abrasímetro fueron cuidadosamente retirados para garantizar el éxito de los restantes tratamientos a ejecutar.

5. Hidrofugante FK 7, distribuido por la casa Fakoliht. 


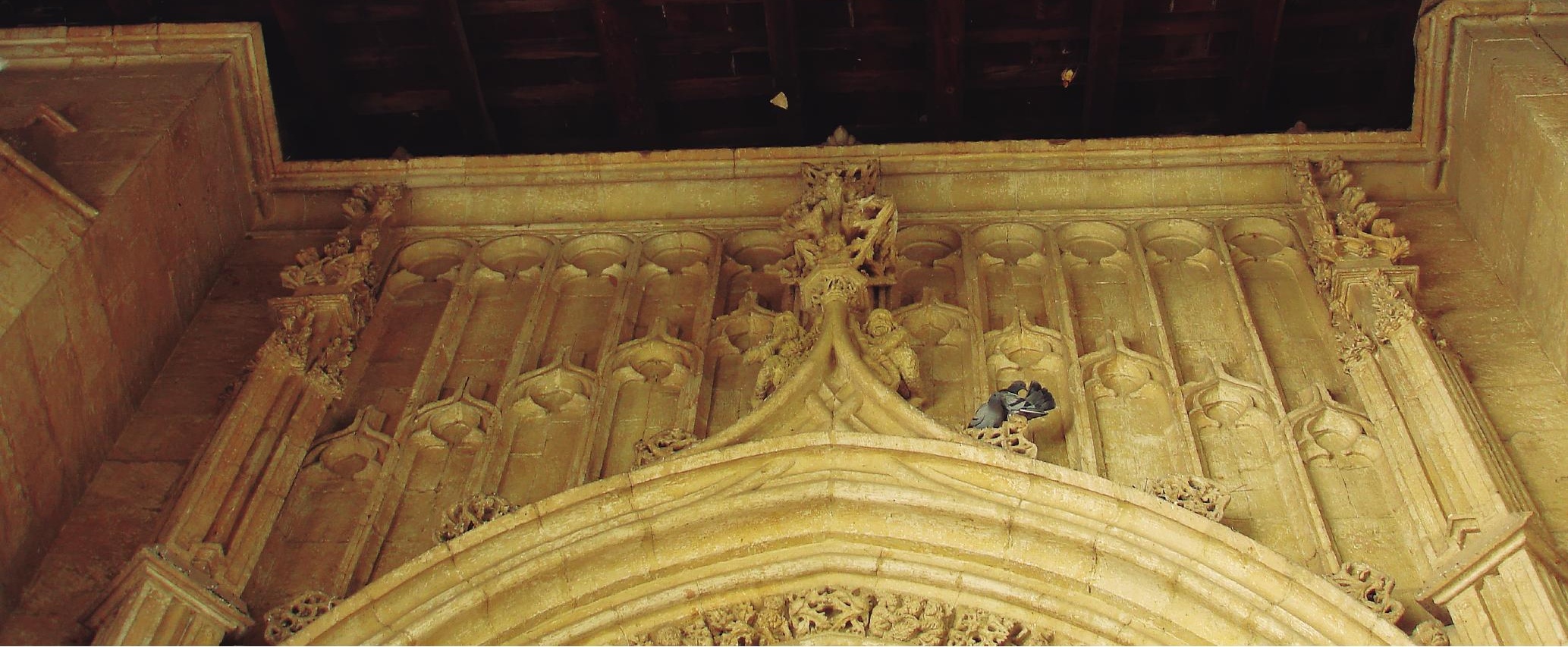

Con el fin de evitar los posibles ataques de xilófagos se aplicó un gel por toda la superficie de la techumbre y sobre la puerta. Una vez terminado el periodo de secado del producto, se eliminaron los barnices oxidados de los clavos y bocallaves de la puerta mediante limpieza química y mecánica. El proceso continuó con la aplicación de un barniz especial para metales, con acabado satinado.

Por último, se finalizaron los trabajos de la puerta, las vigas y la tablazón de la techumbre con varias manos de barniz, también con acabado satinado (Figuras 7 y 8).

\section{Medidas de conservación posteriores a la intervención}

Con el fin de poder conservar todos los valores históricos artísticos que hicieron del convento uno de los bienes arquitectónicos más importantes de Córdoba, es necesario seguir pautas y acciones diarias de mantenimiento y limpieza.

Se recomendó la revisión de la red anti-palomas para evitar el acceso a aves, el depósito de excrementos y de anidamientos en la tracería gótica. El riego con manguera sobre el suelo debe suspenderse para evitar la acumulación de agua tanto en el zócalo como en la puerta. Cuando sea necesaria la limpieza del pavimento es muy importante no pasar el fregón por las zonas bajas del zócalo. De esta manera se conseguirá la perdurabilidad del hidrofugante aplicado y de los pigmentos utilizados para la entonación cromática de los morteros. Así se evitan también manchas en los morteros producidas por los químicos de limpieza.

Para finalizar, se recomendó el uso de un panel móvil tipo caballete para la colocación de cartelería relacionada con las liturgias. De esta manera, se puede localizar la información en la zona deseada por parte de la congregación, y no se producirán agujeros en la puerta ni en el soporte pétreo, con lo cual se evita también los residuos procedentes del celo y oxidaciones (Figura 9).

“Córdoba, milenaria y multicultural, cuna de civilizaciones, donde Oriente y Occidente se funden en un alma.
Figura 7. Estado inicial de la cubierta y segundo cuerpo de la portada Fuente: Noema Wis Molino, 2009. 


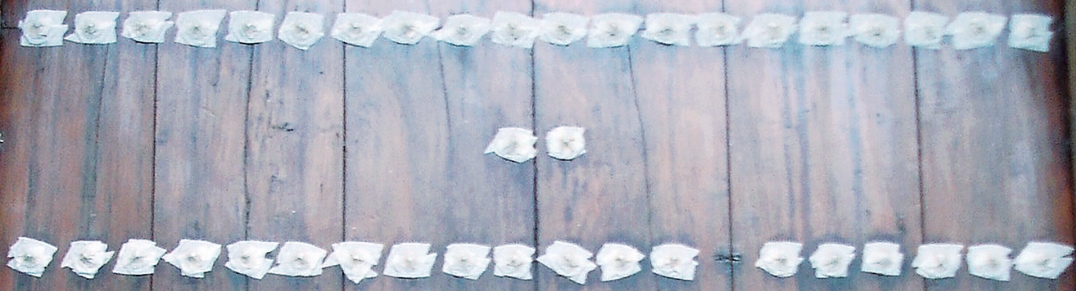

98

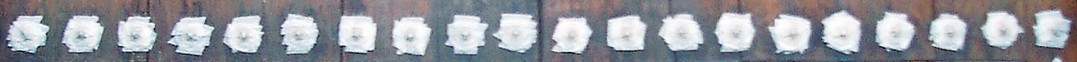

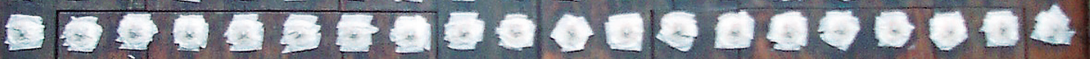

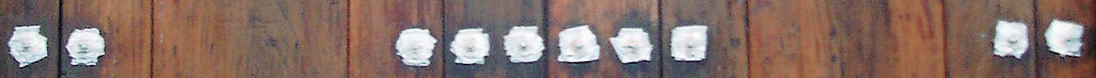

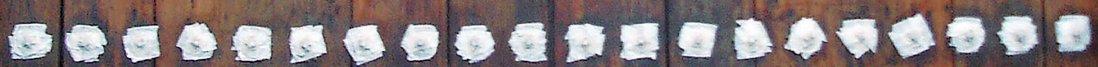
1. 0

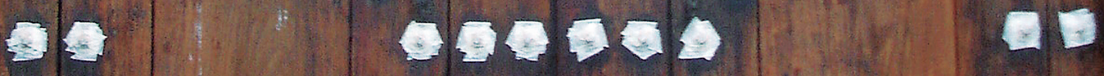

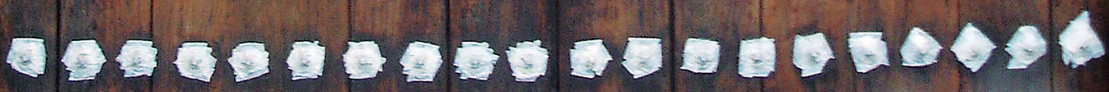
90
$\cos 0$
5

1. 10.40

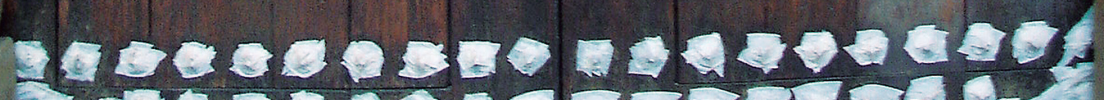
(a)

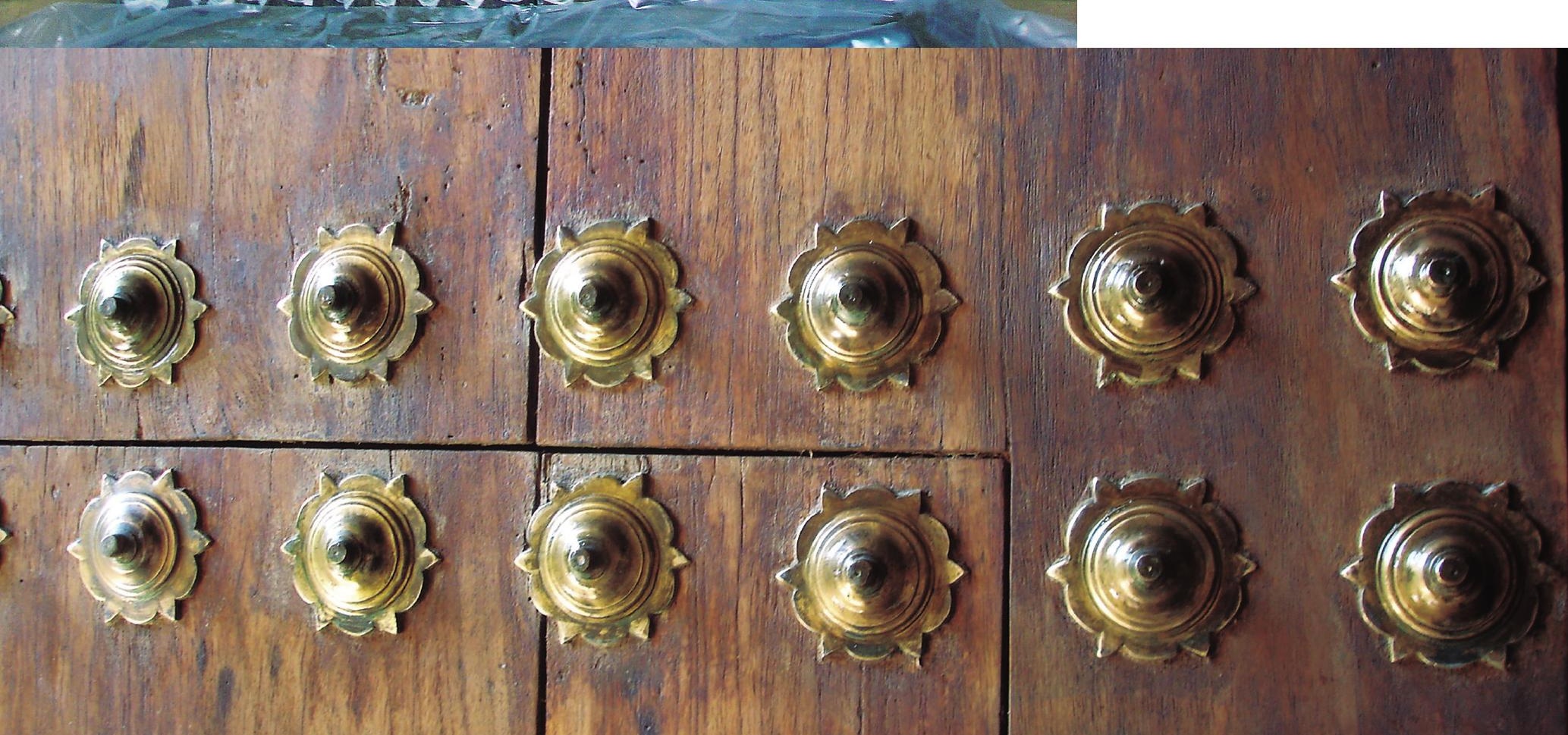

Figura 8. Puerta en proceso de restauración y detalle

Fuente: Noema Wis Molino, 2009. 


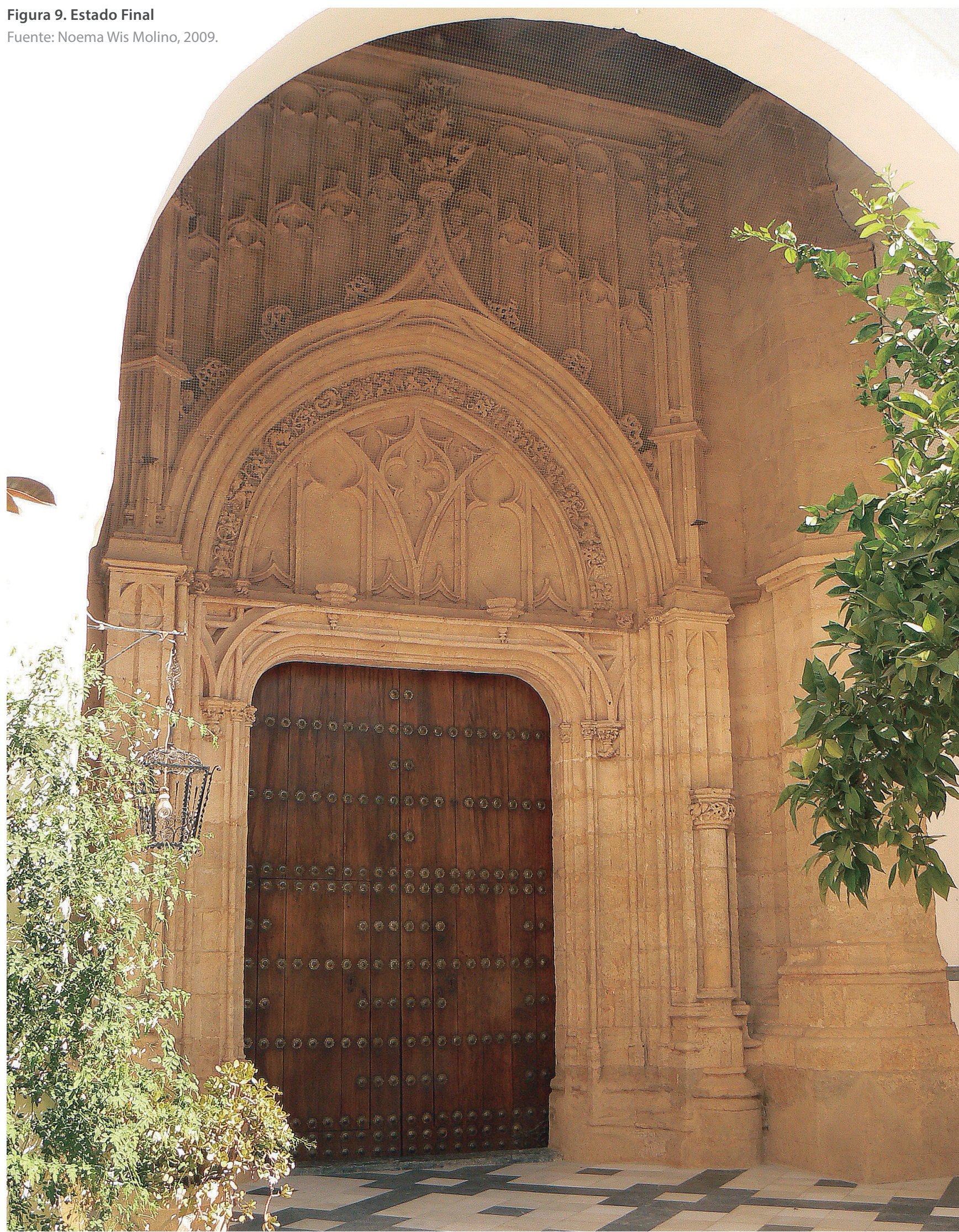


devenir Vol. 4, N7, ENERO- JUNIO 2017, PP. 11-28 - ESTUDIOS | ISSN 2312-7562

UNIVERSIDAD NACIONAL DE INGENIERÍ, LIMA

\section{Referencias}

Alcalde, M., Villegas, R y Martín, A. (2000). Diagnosis y Tratamiento de la piedra II. Consolidantes e hidrófugos. Productos para el tratamiento de materiales. Madrid, España: Instituto de Ciencias de la Construcción Eduardo Torroja.

Arbotante, E. (2009). I Jornadas de Caracterización y Restauración de Materiales Pétreos en Arquitectura, Escultura y Arqueología: Tomo I. Rocas, Morteros y Ladrillos (pp. 1-289). Zaragoza, España: Universidad de Zaragoza.

Benítez, V. B. (2011). La clausura femenina en el mundo hispánico: Una fidelidad secular. En Actas del Simposium (XIX edición) (pp. 959-982). Madrid, España: Instituto Escurialense de Investigaciones Históricas y Artísticas.

De la Banda y Vargas, A. (1974). El arquitecto andaluz Hernán Ruiz Il. Sevilla, España: Universidad de Sevilla.

Gallegos, V. L. (2001). De Corduba a Qurtuba. La Mezquita Catedral de Córdoba, 9, 89-93. Cordoba, España: Diario Córdoba.

Jiménez Salvador, J. L., y Murillo Redondo, J. F. (2002). Nuevas evidencias sobre la Fundación de Corduba y su primera imagen urbana. En J. L. Redondo, Valencia y las primeras ciudades romanas de Hispania (pp. 183-193). Valencia, España: Ayuntamiento de Valencia.

Jordano Barbudo, M. A. (1996). Arquitectura medieval cristiana de Córdoba. Córdoba, España: Universidad de Córdoba.

Luzón, J. M. \& Ruíz Mata, D. (1973). Las raíces de Córdoba. Estratigrafía de la Colina de los Quemados. Córdoba, España: Instituto de Ciencias de la Construcción Eduardo Torroja, Patronato José María Quadrado.

Martín de la Cruz, J. C. (14 de septiembre de 2003). Estudiosos datan los primeros asentamientos de la provincia sobre el 2500 antes Cristo. Diario Córdoba. Recuperado en octubre de 2016 de http://www.diariocordoba.com/noticias/cordobalocal/estudiosos-datan-primeros-asentamientos-provincia-2500-antes-cristo_78720.html

Matuco, E. N. (2003). La carpintería de armar española. Madrid, España: Munilla-lería.

Mazzoli-Guintard, C. (2001). Damasco, Fustat-El Cairo, Qayrawan y Córdoba. En Fundación El Legado Andalusí, El esplendor de los Omeyas cordobeses (pp. 82-95). Córdoba, España: Junta de Andalucía,Consejería de Cultura - Fundación El Legado Andalusí.

Montenegro, E. C. (2016). Relaciones de judíos con cristianos y musulmanes en los siglos XI al XV. Desperta Ferro. Arqueología e Historia., 12-17.

Pérez Higuera, T. (2001). La mezquita de Córdoba. En A. V. Guzmán, El esplendor de los Omeyas cordobeses (p. 372). Córdoba, España: Junta de Andalucía, Consejería de Cultura - Fundación El Legado Andalusí.

Ribera Blanco, J. (2001). De varia restauratione. Valladolid, España: América Ibérica.

Ruiz, P. M. (2001). Crónica latina de los reyes de Castilla. En P. Marfil \& V. Luque Gallegos, Guía visual de la mezquita catedral de Córdoba (pp. 140-150). Cordoba, España: Diario Córdoba.

Souto, J. A. (2009). La mezquita Aljama de Córdoba. Zaragoza, España: Instituto de Estudios Islámicos y del Oriente Próximo. 